Изв. АН Эстонин. Геол. 1989, 38, № 4, 150-154

УДК 551.733.1(474.2)

Сильви МЯГИ, Т. КАЛЛАСТЕ

\title{
КРЕМНИЕВЫЕ КОНКРЕЦИИ В ПОДОШВЕ ГЛАУКОНИТИТОВ ЛЕЭТСЕСКОЙ СВИТЫ СЕВЕРО-ВОСТОЧНОЙ ЭСТОНИИ
}

Нижнеордовикские глауконититы леэтсеской свиты (нижний арениг) на пределе древнепалеозойских терригенных и карбонатных отложений Северной Прибалтики отличаются от ниже- и вышележащих отложений своеобразием минерализации, химизма и генезиса. Известна их связь с аутигенным фосфато- и карбонатообразованием.

Нами установлено окремнение в основании глауконититов леэтсеской свиты Северо-Восточной Эстонии (в промежутке между рр. Пуртсе и Нарва): небольшие линзочки, гнезда, а также поверхности перерыва с белым, местами слегка кремовым тонкодисперсным материалом. По внешнему виду эти проявления напоминают перекристаллизованное карбонатное или фосфатное вещество и при макроописании разрезов ранее не отмечены.

Наиболее выразительное окремнение наблюдается в обн. Лангевоя южнее г. Силламяэ, где на сильно обохренной желтоватой поверхности тремадокских коричневых керогенистых аргиллитов тюрисалуской свиты $(1,2 \mathrm{M}+)$ залегает пестроцветный пелитовый слой мощностью $0,1 \mathrm{~m}$. В нем чередуются (интервалом $1-2$ мм) слои: светло-серый, фиолетовый, светло-серый, белый (в последней разновидности отмечаются кремниевые стяжения $2-3$ см), а также зеленый алевритовый и коричневый лимонитизированный.

Выше залегают глауконититы леэтсеской свиты: темно-зеленый песчано-глинистый глауконитовый алеврит йоаской пачки $(5-10$ см) и крепкосцементипованный кварц-глауконитовый алевролит мяэкюлаской пачки (30 см). Последний богат светло-серыми пелитовыми ходами илоедов, в нижней части комковатый, в верхней - толстослоистый.

Кремниевые стяжения в глинистом слое основания йоаской пачки покрыты кварцево-глауконитовым глинистым алевритом. На контакте со стяжениями наблюдается в породе тонкая $(1-2$ мм) темно-копичневая корковидная каемка с гидроокислами железа, единичными окатанными зернами кварца и измененными зернами глауконита, местами с пиритом. Концентрация гидроокислов железа усиливается в стопону поверхности конкреший и контакт этой полосы лимонитизашии очень четкий, маркирован остатками пиритовой пленки. В обратную сторону интенсивность импрегнации железистыми соединениями постепенно уменьшается (табл. I, 2, 3).

В строении самих конкреций преобладает слегка кремовый материал, окруженный с внешней стороны микрокристаллической, почти аморфной коркой $(2-3$ мм). В основном материале встречены каверны и поры, стенки которых также покрыты белой неровной почковидной копкой (мошность менее 2. мм), а также желтым налетом гидроокислов железа и рассеянной вкрапленностью яркокрасного гематита. В кавернах встречены зерна глауконита и аллотигенного кварца. Часто наблюдаются в кремовой микрокристаллической основной массе измененные палочковидные или незакономерной формы белые, возможно, биогенные образования (спикулы губок?) и трубочко-, конусо- и пузырьковидные черные образования диаметром $\sim 0,1-0,2$ мм, представленные хитинозоями и детритом граптолитов (табл. I, II). В скрещенных николях под 
микроскопом прослеживаются микрокристаллы с рефлексами кварца. В химлаборатории ИГ АН ЭССР (Ы. Роос) определен следующий состав конкреций $(\%): \mathrm{SiO}_{2}-83,88 ; \mathrm{TiO}_{2}-0,34 ; \mathrm{Al}_{2} \mathrm{O}_{3}-6,50 ; \mathrm{Fe}_{2} \mathrm{O}_{3}-3,39$; $\mathrm{MgO}-0,86 ; \mathrm{CaO}-0,39 ; \mathrm{CO}_{2}-$ не установлено; $\mathrm{P}_{2} \mathrm{O}_{5}-1,32 ;$ п. п. п. (при $\left.900^{\circ} \mathrm{C}\right)-3,60$.

При обработке ультразвуком получены микрокристаллическая и кусковая фракция конкреций, дифрактограммы которых идентичны (рис. 1, 2).

Рентгенометрические исследования проведены на дифрактометре ДРОН-2.0 (трубка БСВ-22 Cu). Дифрактограмма показывает чистый $\alpha$-кварц с несколько искаженным соотношением интенсивностей (интенсивность рефлекса 102 увеличена и рефлекса 110 уменьшена) (рис. $1, A$ ). Особый снимок показывает малую примесь пирита и франколита $(0,5-$ $1 \%$ ). Примесь аморфной окиси железа, вероятно, обусловила повышение фона дифрактограммы. Для освобождения от фона и в интересах более точной диагностики минералов, проба промыта в растворе $2 \mathrm{NHCl}$. Для сравнения параметров использован препарат эталонного кварца, изготовленного из кристаллического кварца (диаметр частиц $<0,02$ мкм), нагретого при $600^{\circ} \mathrm{C}$.

Сравнение дифрактограмм триплета рефлексов 212, 203, 301 эталона и исследуемого кварца показывает пониженную кристалличность кварца (рис. 2). Причиной расширения рефлексов дифракции могут служить малые размеры ( $<0,1$ мкм) монокристаллических блоков или микродеформации кристаллической решетки. Для выяснения этого вопроса использован метод интегральной полуширины рефлекса (Иверонова, Ревкевич, 1978; Кривоконева, 1980), предполагая, что профили рефлексов описываются формулой

$$
f(x)=f(0) \frac{1}{1+\alpha x^{2}} .
$$

Полученные замеры показывают, что низкая кристалличность исследованного кварца обусловлена микродеформациями кристаллической решетки (рис. $1, Б$ ). Отмечается и зависимость расширения рефлекса от кристаллических индексов (анизотропные деформации). Определены следующие средние относительные вариации параметров решетки:

$$
\left(\frac{\Delta a}{a}\right)=0,0010 \text { (по рефлексу 220) и }\left(\frac{\Delta c}{c}\right)=0,0007 \text { (по рефлексу 104) }
$$

(рис. 1,5$)$.

Средние размеры блоков когерентного рассеяния больше $5000 \AA$ (0,5 мкм). Интегральные интенсивности измеренных рефлексов исследованного кварца (индексы на рис. 1,5 ) составляли от интенсивностей соответствующих рефлексов эталонного кварца 96-102\% (средний $98 \%$ ). Следовательно, $\mathrm{SiO}_{2}$ в исследованной пробе полностью кристаллизован ( $\alpha$-кварц).

Параметры решетки замерены по центрам тяжести рефлексов 104 и 220 , для конкреции кварца они больше эталонного на $0,002-0,003 \AA(a)$ и $0,000-0,001 \AA(c)$. Для столь малых отклонений необходима большая точность измерений (ошибка $<10^{-4} \AA$ ), но все-же выявленная тенденция не вызывает сомнений. Расширение решетки обусловлено, видимо, присутствием изоморфной примеси, от распределения которой в структуре зависит и вариация параметров решетки.

Помимо изученных образцов снято еще несколько дифрактограмм кремниевых гнезд из отложений, подстилающих глауконититы. Наличие в них низкокристалличного кварца и некоторые другие признаки указывают на сходство с материалом кремниевых конкреций из глауконитита. Возможно их близкое биохемогенное происхождение. 

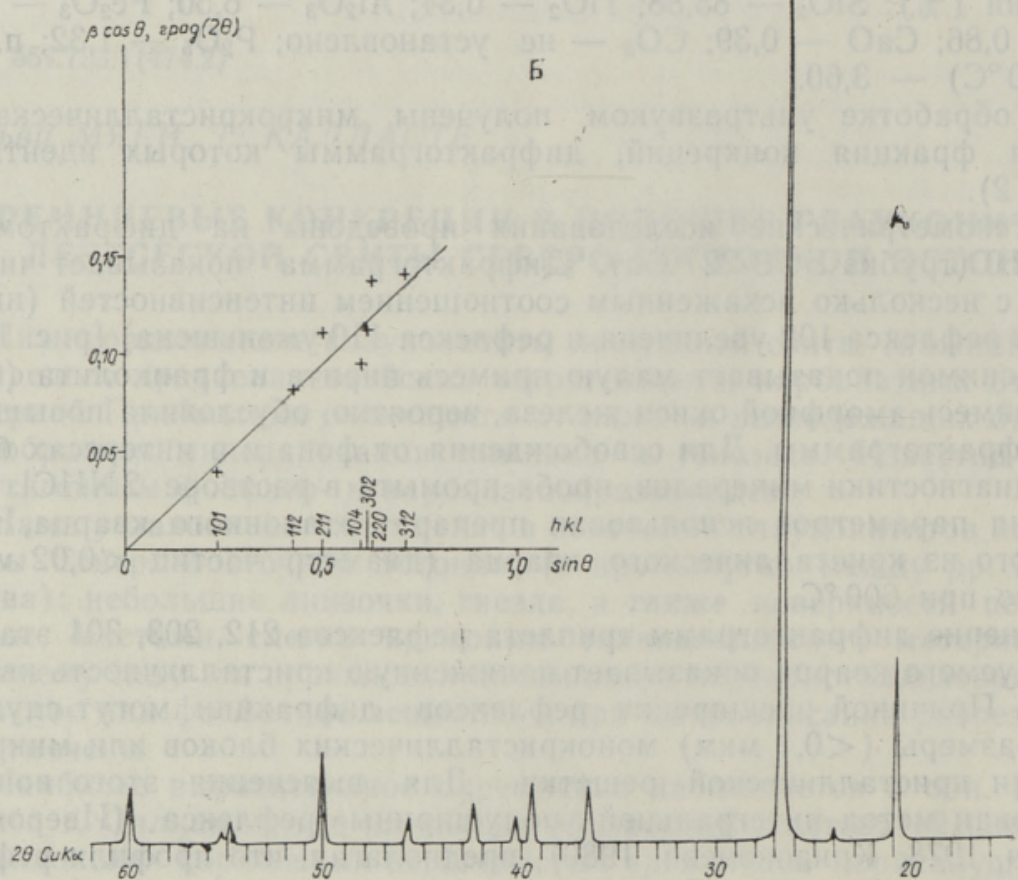

Рис. 1. Участок дифрактограммы $(A)$ и график дифракционного размытия для определения величины микродеформации (Б).

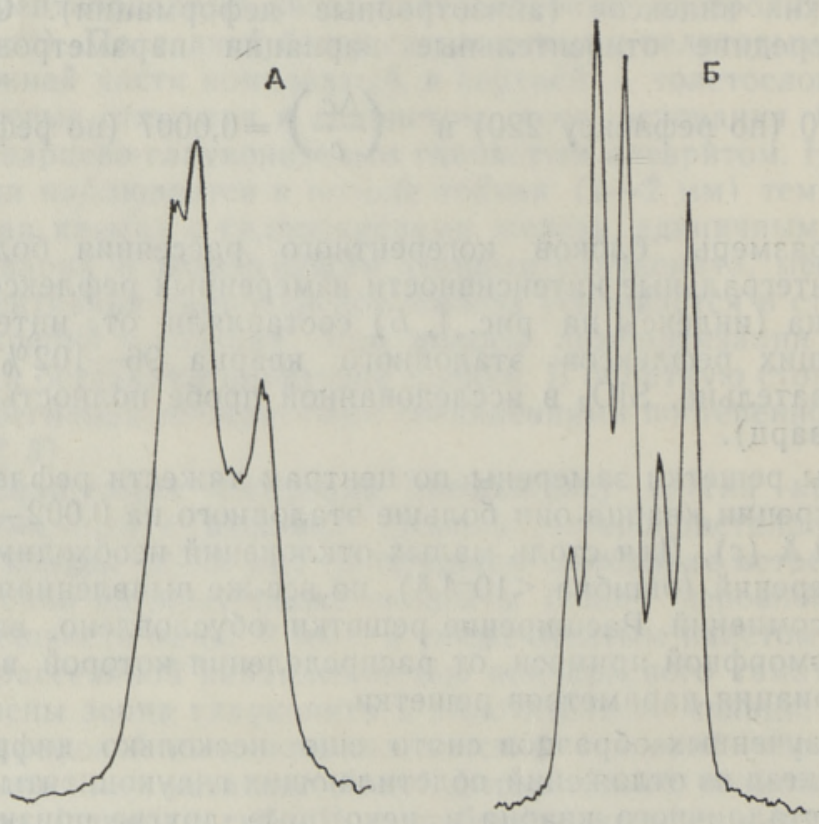

Рис. 2. Триплет рефлексов 212, 203, 301 иселедованного $(A)$ и эталонного (Б) кварца. 


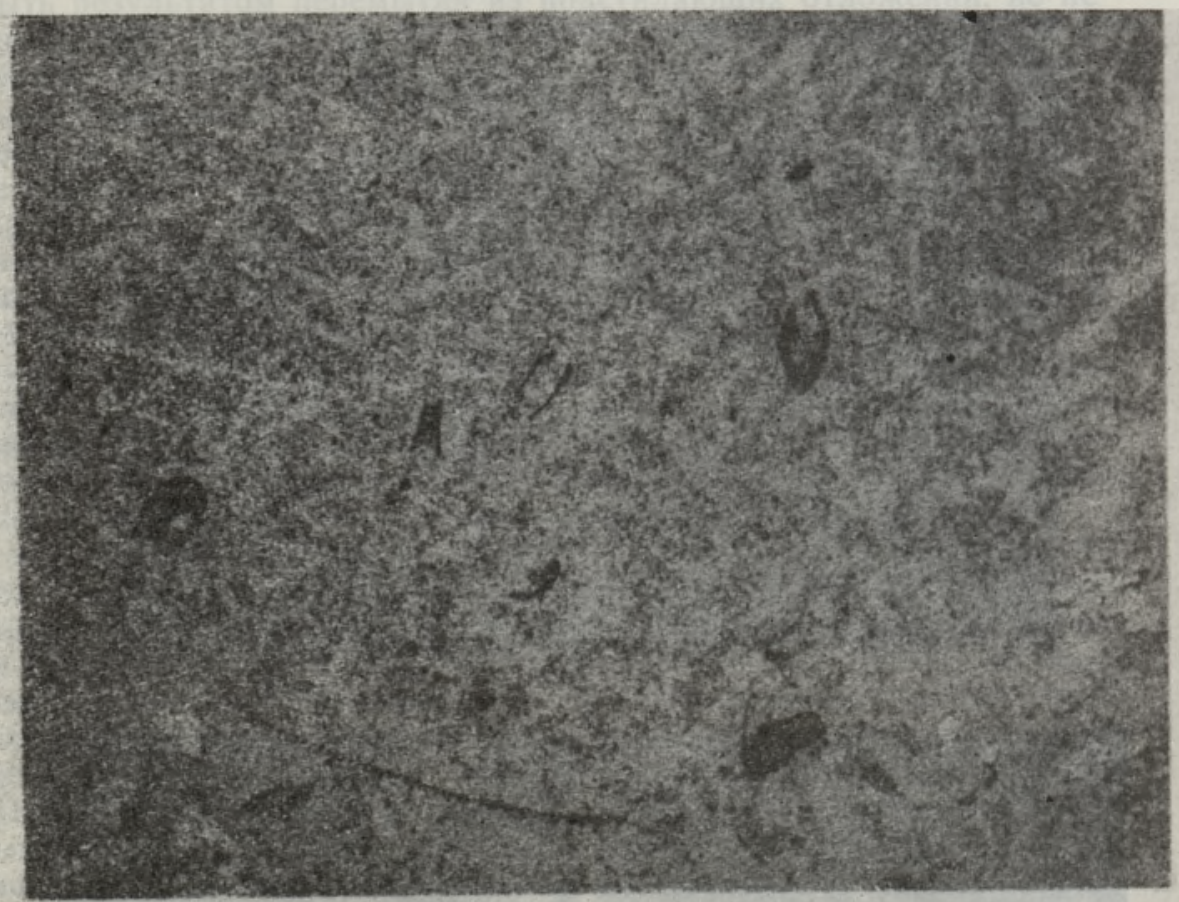

\section{1}

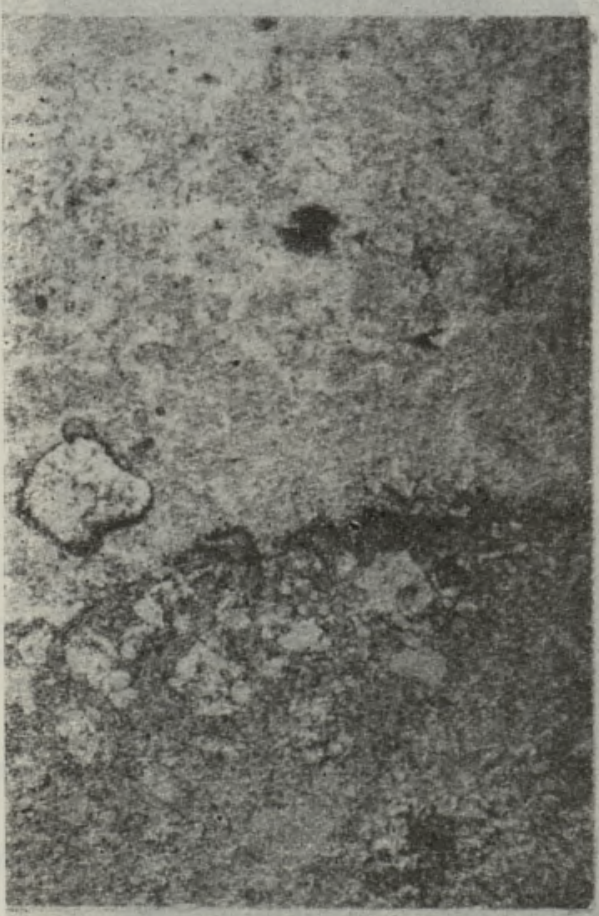

2

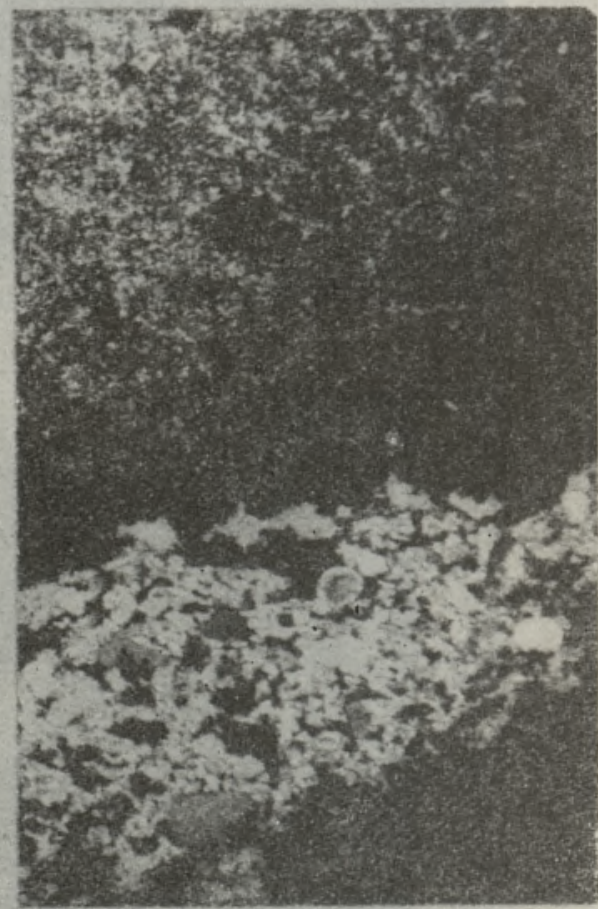

3

Органогенно-микрокристаллическая внутренная структура кремниевых стяжений $(1)$.

Увел. $20 \times$, ннк. 1. Контакт конкрецни (верхняя часть) с глауконититом $(2,3)$. Увел. 16 X. 2 - ник. $1 ; 3-$ ник. $\times$. 


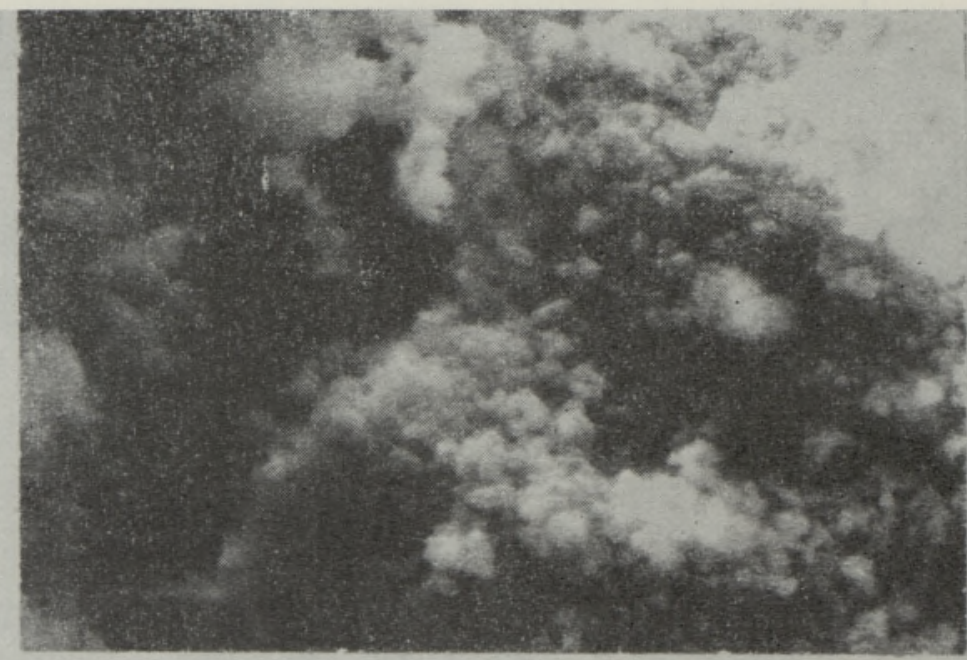

\section{1}

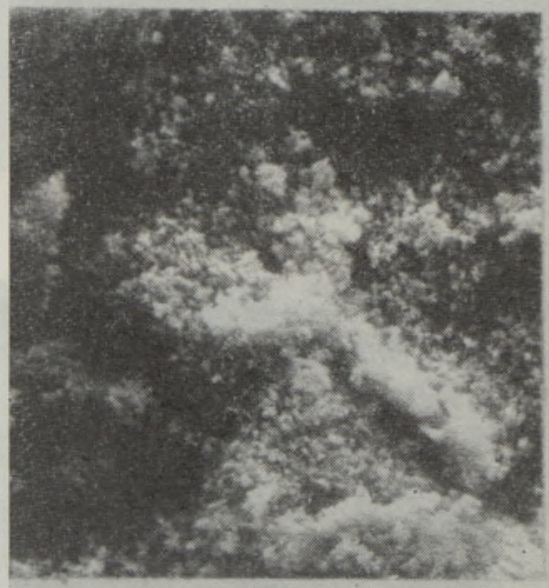

2

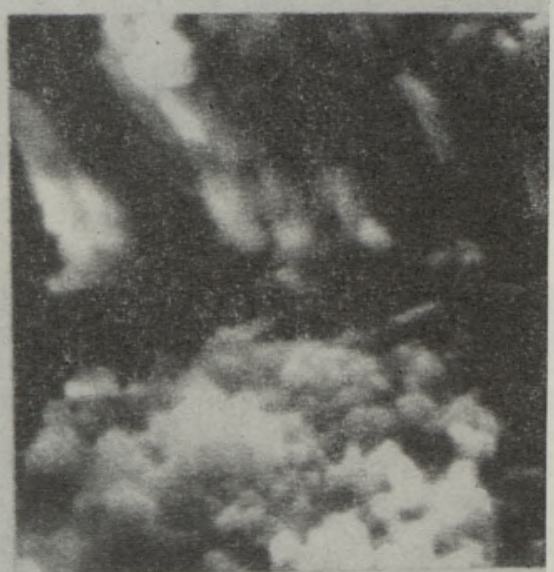

3

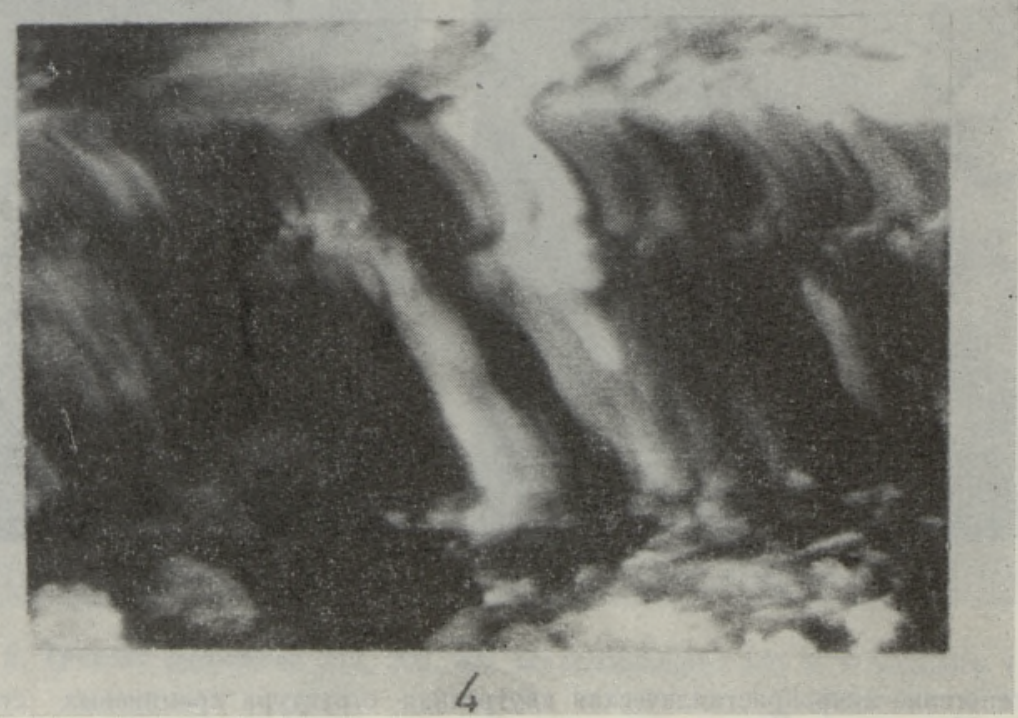

Микрокристаллическая пористая структура основной массы кремниевой конкреции $(1,2) .1-8000 \times ; 2-1000 \times$. Микрочешуйчатая структура внутренного строения агрегатов $(3,4), 6300 \times$. Фото выполнено на СЭМ. 
Кремниевые образования в подстилающих керогенистых аргиллитах описаны ранее К. Мююрисеппом (Мüürisepp, 1964). Их возникновение могло быть результатом перемытия из подстилающих отложений, но не исключено их образование и в самих глауконититах.

Отдельные участки слоя, вмещающего кремниевые конкреции, напоминают среднеордовикские и силурийские метабентониты Эстонии. Окремнение во вмещающих метабентониты слоях обычное явление: присутствие метабентонитов отмечается в нижнем ордовике соседних регионов (Скандинавия, Польша). Имеются также представления (Фролов, 1984; Ван, Қазанский, 1985), по которым образование как подстилающих темных аргиллитов, так и самих глауконититов происходило под влиянием вулканической деятельности.

С другой стороны, пелитовый слой с кремниями на контакте тремадока и аренига находится на выветрелой јповерхности перерыва, соответствующей значительному седиментационному пробелу в объеме всего верхнего тремадока и нижнего аренига. Поэтому образование конкреций можно связывать и с процессами выветривания.

Так, к востоку от Лангевоя, в районе Нарва, а также на юге выклиниваются подстилающие граптолитовые аргиллиты, залегающие над ними серые глины тремадока и сами глауконититы нижнего аренига. Остатки средне-аренигских глауконититов залегают практически на оболовых песчаниках. Как последние, так и вышележащие карбонатные аренигские отложения отличаются здесь от соответствующих отложений Западной Эстонии интенсивной гематитизацией и красноцветностью пород. По этой причине в рассмотренном районе с дифференцированным блоковым тектоническим строением могли сохраниться к началу аренига отдельные участки, потерпевшие усиленное выветривание с преобразованием и перераспределением материала. Аренигские отложения в целом образовались в условиях трансгрессии моря, воды которой обогатились разными компонентами выветривания, в том числе и теми, которые необходимы для образования глауконита. Местами в прослоях онтикаских отложений (обн. Нарва, недалеко от обн. Лангевоя и др.) определено содержание $\mathrm{Al}_{2} \mathrm{O}_{3}$ в породе свыше $50 \%$. Оно указывает на возможность в породах присутствия свободных окислов глинозема явного продукта выветривания.

Окончательный ответ на вопросы генезиса кремниевых конкреций, а также других видов аномальной минерализации должны дать дополнительные исследования всех соответствующих проявлений.

\section{ЛИТЕРАТУРА}

Ван А. В., Казанский Ю. П. Вулканокластический материал в осадках и осадочных по. родах. Вып. 614. Новосибирск, 1985.

Нверонова В. И., Ревкевич Г. П. Теория рассеянных рентгеновских лучей. М., 1978.

Кривоконева $Г$. K. Рентгенографическое определение структурных нарушеннй флюорнта // Рентrенография минерального сырья и ее прикладное значение. М., 1980, $189-197$

Фролов В. T. Генетическая типизация морских отложений. М., 1984.

Müürisepp, K. Käsnaläätsedest pakerordi lademes // LUS-i aastaraamat, 1964, 56, 17-24.

Институт геологии

Академии наук Эстонской ССР
Поступила в редакцию 4/VIII 1988 
Silvi MAGI, T. KALLASTE

\section{RÄNIKONKRETSIOONID KIRDE-EESTI LEETSE KIHISTU GLAUKONITIITIDE \\ ALLOSAS}

On iseloomustatud seni kirjeldamata valkjate ränikonkretsioonide kihti Kirde-Eesti Leetse kihistu all lasuvas kirjuvärvilises peenekihilises peliidis ning antud konkretsioonide räniaine keemiline koostis ja struktuuri iseärasused röntgenograafilise uuringu põhjal.

Silvi MAGI, T. KALLASTE

\section{SILICEOUS CONCRETIONS AT THE BASE OF THE GLAUCONITIC LEETSE FORMATION OF NORTH-EAST ESTONIA}

White chemogenic concretions in the pelitic bed at the base of the Arenigian glauconitic Leetse Formation exposed in the North-East Estonian Langevoja outcrop are characterized. The chemical composition and the roentgenite structure of the concretions have been studied. 